\title{
Mucoadhesive System To Enhance Drug Activity Containing Flurbiprofen As Model Drug
}

\author{
Waqar Siddique ${ }^{a^{*}}$, Farhan asghar ${ }^{\mathrm{b}}$, Sarfraz ahmad ${ }^{\mathrm{c}}$, Maria gul ${ }^{\mathrm{d}}$, Tangina Malik \\ *wpharmacist@gmail.com \\ a,b,c,d,e School of Pharmaceutical Sciences (SPS), Johar Institute of Professional Studies (JIPS), Lahore, 54000, \\ Pakistan.
}

\begin{abstract}
To develop bucaal mucoadhesive drug delivery system which retains and diffuses drug for a prolonged period of time. Flurbiprofen due to its use in elderly patients for the symptoms of joint pain as well as in dental issues, Aim is to facilit ate patients by prolonging the delivery of drug substance by formulating mucoadhseive system. Mucoadhesive poly mers like HPMC, Sodium carboxy methyl cellulose and carbopol were used to formulate the tablets by using direct compression method. Characterization of the tablets was done to confirm their usability. Results, indicate that the formulations no F8, F9 and F12 which were prepared by using Carbopol 971 shows better $\mathrm{pH}$, mucoadhesive and release retarding effect. So, it is concluded that carbopol has excellent water retaining properties and it also retards the drug.
\end{abstract}

Published by IJRP.ORG. Selection and/or peer-review under responsibility of International Journal of Research Publications (IJRP.ORG)

Keywords: Mucoadhesive drug delivery system; Dry granulation technique; in-vitro characterization.

\section{Introduction}

The term "Adhesion" it simply depicts the process in which the two surfaces are attached or fixed with each other. The definition of that particular term changes depending upon the nature of its use(Manogna, Nagaveni et al.). Finally the term "Bioadhesion" is defined as a system in which there appears a force of attraction between the polymer and the biological membrane. This force of attraction / adhesion provides the adherence of the polymer at the biological membrane for a prolonged period of time. As many alternate routes of drug administration are available but oral route is most preferable route of drug administration(Reddy, Anjum et al. 2013). Oral route is also divided into many types but this route is limited depending upon the active moiety and dos age form. High first pass metabolism and degradation of drugs especially proteins and peptides in stomach make this route a less selective than other routes of drug administration. Here comes an alternative route to oral route is the buccal ad ministration of the drugs, especially the buccal adhesive drug delivery system. Mucous membrane present in oral cavity provides a best opportunity for administration of medications. This route of drug administration provides the opportunity for both local as well as systemic delivery of the active drugs(Singh and Deep 2013). Other than buccal route drugs can be administered by nasal as well as by vaginal route where the mucous membranes are present(Gupta, Singhvi et al. 2011). Oral region further divides into sublingual, buccal and local drug delivery based on the method of drug delivery. In case, of sublingual drug delivery the dosage form is placed on the floor of the oral cavity beneath the tongue. While, for Buccal delivery drug in which the dosage form is placed within the mucosal lining against the 
cheeks wall. And for local delivery in which the drug is delivered inside the oral cavity region(Reddy, Anjum et al. 2013).

\section{Materials and Methods}

\subsection{Materials}

Flurbiprofen received as a gift sample from CCl Pharma Pvt Ltd, Methocel K4M and K15M are purchased from sigma Aldrich, Sodium CMC, Lactose (Anhydrous), Talc and Magnesium Stearate were purchased from Fluka international. All ingredients were of analytical grade

\subsection{Method}

Flurbiprofen was used as a model drug for the preparation of mucoadhesive tablets. Buccal adhesive tablets were prepared by direct compression method using different polymers which includes HPMC K4M, HPMC K15M, Sodium carboxy methyl cellulose (Na CMC), and carbopol. All of these polymers were employed in varying concentration as depicts in table no 1 . All of the ingredients used were of analytical grade. First of all the ingredients are weighed accordingly, then they are mixed in a mortal and pestle. In the last stages for the sake of lubrication magnesium stearate and talc was added. The finally mixed material was slightly compressed on the $6 \mathrm{~mm}$ flat faced punch by using direct compression method. The total weight of the formulation was maintained $294 \mathrm{mg}$ (Kadam, Yeole et al. 2014).

Table 1. Formulation profile for bioadhesive buccal tablets

\begin{tabular}{|c|c|c|c|c|c|c|c|c|c|c|c|c|}
\hline Ingredients Mg/Tablet & $\mathrm{F}_{1}$ & $\mathrm{~F}_{2}$ & $\mathrm{~F}_{3}$ & $\mathrm{~F}_{4}$ & $\mathrm{~F}_{5}$ & $\mathrm{~F}_{6}$ & $\mathrm{~F}_{7}$ & $\mathrm{~F}_{8}$ & $\mathrm{~F}_{9}$ & $\mathrm{~F}_{10}$ & $\mathrm{~F}_{11}$ & $\mathrm{~F}_{12}$ \\
\hline Flurbiprofen & 200 & 200 & 200 & 200 & 200 & 200 & 200 & 200 & 200 & 200 & 200 & 200 \\
\hline HPMC k4M & 35 & ---- & ---- & --- & 17.5 & 17.5 & ---- & ---- & 27.5 & 11.7 & ---- & - \\
\hline HPMC k15M & - & 35 & --- & ---- & 17.5 & - & 17.5 & ---- & - & ---- & 11.7 & - \\
\hline Carbopol 971p & - & --- & 7.5 & --- & --- & - & --- & 7.5 & 7.5 & ---- & --- & 5 \\
\hline Sodium CMC & - & ---- & ---- & 35 & ---- & 17.5 & 17.5 & 27.5 & - & 23.3 & 23.3 & 30 \\
\hline Lactose & 55 & 55 & 82.5 & 55 & 55 & 55 & 55 & 55 & 55 & 55 & 55 & 55 \\
\hline $\begin{array}{l}\text { Magnesium } \\
\text { stearate }\end{array}$ & 1.75 & 1.75 & 1.75 & 1.75 & 1.75 & 1.75 & 1.75 & 1.75 & 1.75 & 1.75 & 1.75 & 1.75 \\
\hline Talc & 2 & 2 & 2 & 2 & 2 & 2 & 2 & 2 & 2 & 2 & 2 & 2 \\
\hline Total (mg) & 294 & 294 & 294 & 294 & 294 & 294 & 294 & 294 & 294 & 294 & 294 & 294 \\
\hline
\end{tabular}

\subsection{Characteristics}

\subsubsection{Physicochemical evaluation ofbuccal tablet}

\section{a. Weight variation}

Pick randomly ten tablets, then weights them and calculate their average weight.

\section{b. Hardness}

Hardness of the prepared tablets checked by picking three tablets from each prepared batch and then checked hardness by using Monsanto hardness tester and average values of the tables calculated. 


\section{c. Friability}

Friability of the tablets is checked in order to justify the loss of tablets due to shock. Six tablets were selected and placed in the plastic chamber of friabilator revolving at $25 \mathrm{rpm}$ for $4 \mathrm{~min}$. Roche friabilator was used for that test conduction. Tablets weighed before and after the completion of the test.

\section{d. Thickness}

Micro meter screw gauge was used in order to determine the average thickness of the formu lated tablets. From each batch ten tablets were selected and then their average is noted.

\subsection{Content uniformity}

Randomly five tablets were selected than they are grounded into a fine powder by using mortar and pestle. Grounded tablets must be equal to a single dose. The powder is then dissolved in methanol solution. The prepared mixture is then sonicated for about 15 minutes. After sonication the resultant mixture passes through Whatmann filter paper having pore size $0.45 \mu \mathrm{m}$. In order to confirm the presence of drug content it is than was analyzed spectrophotometrically at $281 \mathrm{~nm}$ using a UV spectrophotometer single beam. The process is repeated for three times and the average is noted(Patel, Shah et al. 2014).

\subsection{Swelling study}

Weight (W1) represents the weight of individual tablet which is then placed on a agar gel plate having a concentration of $2 \%$ at $37 \pm 1^{\circ} \mathrm{C}$ in incubator. After time starting from 1 hour to 6 hours tablets were taken out and the extra water is then removed by using filter paper a suitable absorbent. Now, another weight (W2) appeared which represent the weight of swollen tablets. By using the given formula the swelling index of the tablets was calculated.

$\mathrm{SI}=(\mathrm{W} 2-\mathrm{W} 1) \mathrm{W} 1$

\subsection{Surface $\mathrm{pH}$}

$\mathrm{pH}$ of the prepared tablets is an important characterization because acidic or basic both $\mathrm{pH}$ can irritate the buccal mucosa. That is why the $\mathrm{pH}$ of the formulated tablets is kept possibly near the neutral $7 \mathrm{pH}$. To perform this test tablets are placed in a $6.8 \mathrm{pH}$ media with $2 \mathrm{ml}$ saliva flu id for approximately 2 hours. Now the $\mathrm{pH}$ of the tablets is determined by touching the tablet surface with $\mathrm{pH}$ electrode. All of the readings were taken three times and their mean is then calculated.

\subsection{In vitro mucoadhesive force}

To study bio adhesion of prepared tablets the two-armed balance method by making slight modifications was used. Eggshell membrane of a fresh egg was used for this process. Membrane removed from egg shell was stuck at the base of a small size beaker which is further attached to a large sized beaker. Phosphate buffer having pH 6.8 was then poured on the beaker on the upper surface of the egg membrane. Finally tablet was attached at the upper side of the clamp and the assembly was slowly raised until the tablet and membrane come in contact with each other. Waiting for 5 minutes, water is then added to the tablet is detached. The weight of the water in grams, which detaches the tablet will provide us the strength of bioadhesive force, which further is calculated using the equation.

Force of adhesion $(\mathrm{N})=$ bioadhesive strength $\times 9.81 / 1,000$

\subsection{In vitro drug release study}


USP dissolution apparatus with rotating paddle apparatus was used to study the drug release pattern from the prepared mucoadhesive tablets. Phosphate buffer with pH 6.8 was used. The baskets were filled $250 \mathrm{ml}$ with prepared buffer. Rotating paddles were fixed at $50 \mathrm{rpm}$ at a temperature fixed at $37 \pm 0.5^{\circ} \mathrm{C}$. Buccal tablets were attached to a glass disk than placed at the base of the baskets. Aliquot quantity of about $5 \mathrm{ml}$ sample than taken from the basket and is placed with the fresh sample. Obtained sample is than filtered through $0.45-\mu \mathrm{m}$ sized filter. Than proper dilutions are made and observed under single beam spectroscopy at $281 \mathrm{~nm}$ wavelength(Darwish and Elmeshad 2009).

\section{Results and Discussion}

\subsection{Physicochemical evaluation ofbuccal tablet}

Hardness of the formulated tablets was shown within the range of $8.2 \pm 0.10$ to $6.5 \pm 0.14$. While weight variation which is approximately up to $100 \%$ shows that there is low variation in the tablets binding and the loss of content is less also. Percentage friability ranges from 0.01 to 0.31 which also shows there is less loss of drug powder from the formulated tablets. Drug content analysis shows that the drug is properly blended with in the tablets and ranges from $101.45 \pm 0.51$ to $98.43 \pm 0.23$ from maximum to minimum value.

Table 2. Physicochemical evaluation of buccal tablets

\begin{tabular}{|c|c|c|c|c|c|c|}
\hline Formulation no. & $\begin{array}{l}\text { Hardness } \\
\left(\mathrm{Kg} / \mathrm{Cm}^{2}\right) \\
\text { Mean } \pm \text { S.D. }\end{array}$ & $\begin{array}{l}\text { Thickness }(\mathrm{mm}) \\
\text { Mean } \pm \text { S.D. }\end{array}$ & $\begin{array}{l}\text { Weight } \\
\text { variation }(\mathrm{mg}) \\
\text { Mean } \pm \text { S.D. }\end{array}$ & $\%$ & $\begin{array}{c}\text { Drug Content } \\
\text { Mean } \pm \text { S.D. }\end{array}$ & $\%$ \\
\hline $\mathrm{F}_{1}$ & $8.0 \pm 0.19$ & $3.61 \pm 0.05$ & $101.34 \pm 3.85$ & 0.01 & $100.98 \pm 0.31$ & \\
\hline $\mathrm{F}_{2}$ & $8.2 \pm 0.10$ & $3.60 \pm 0.05$ & $99.12 \pm 4.89$ & 0.02 & $101.42 \pm 0.32$ & \\
\hline $\mathrm{F}_{3}$ & $6.5 \pm 0.14$ & $3.58 \pm 0.05$ & $101.17 \pm 1.62$ & 0.31 & $101.45 \pm 0.51$ & \\
\hline $\mathrm{F}_{4}$ & $7.6 \pm 0.46$ & $3.58 \pm 0.05$ & $98.48 \pm 1.71$ & 0.25 & $99.69 \pm 0.05$ & \\
\hline $\mathrm{F}_{5}$ & $7.5 \pm 0.10$ & $3.64 \pm 0.09$ & $101.88 \pm 1.59$ & 0.15 & $99.35 \pm 0.31$ & \\
\hline $\mathrm{F}_{6}$ & $7.8 \pm 0.12$ & $3.61 \pm 0.05$ & $99.85 \pm 1.24$ & 0.02 & $98.43 \pm 0.23$ & \\
\hline $\mathrm{F}_{7}$ & $7.5 \pm 0.12$ & $3.62 \pm 0.05$ & $99.92 \pm 1.95$ & 0.30 & $101.23 \pm 0.21$ & \\
\hline $\mathrm{F}_{8}$ & $8.0 \pm 0.32$ & $3.57 \pm 0.05$ & $100.54 \pm 2.14$ & 0.31 & $100.99 \pm 0.22$ & \\
\hline $\mathrm{F}_{9}$ & $7.9 \pm 0.42$ & $3.60 \pm 0.05$ & $101.85 \pm 2.16$ & 0.01 & $99.63 \pm 0.26$ & \\
\hline $\mathrm{F}_{10}$ & $7.3 \pm 0.12$ & $3.61 \pm 0.01$ & $99.89 \pm 1.99$ & 0.25 & $100.10 \pm 0.50$ & \\
\hline$F_{11}$ & $7.2 \pm 0.24$ & $3.60 \pm 0.05$ & $99.83 \pm 2.33$ & 0.04 & $101.91 \pm 0.03$ & \\
\hline $\mathrm{F}_{12}$ & $7.6 \pm 0.19$ & $3.60 \pm 0.01$ & $99.15 \pm 1.63$ & 0.05 & $100.56 \pm 0.00$ & \\
\hline
\end{tabular}

\subsection{Swelling studies}


Swelling studies were performed on the prepared tablets for 1 hour to 06 hours. In itially the tablet was very s mooth and then it absorbs the varying amount of water depending upon the water swelling ability of the polymer as shown in figure.

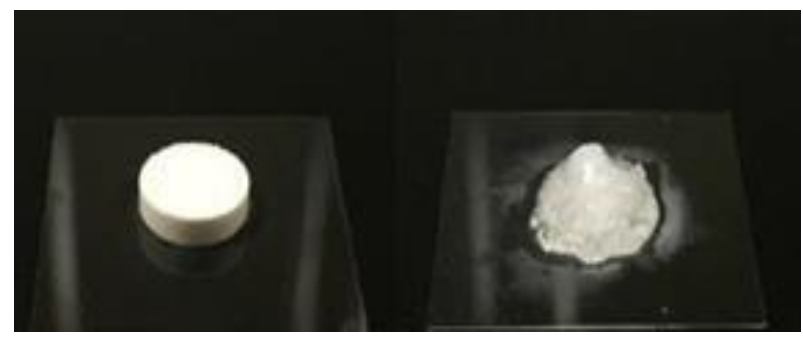

Figure 1. Representing the swelling behavior of buccal tablet

Table 3. Buccal tablet swelling profile

\begin{tabular}{|c|c|c|c|c|}
\hline \multirow{2}{*}{ Formulation No } & \multicolumn{4}{|c|}{$\%$ Swelling Index (Mean \pm S.D.) Time (Hours) } \\
\hline & 1 & 2 & 4 & 6 \\
\hline $\mathrm{F}_{1}$ & $36.96+0.25$ & $32.11+0.41$ & $54.39+0.43$ & $48.33+0.45$ \\
\hline $\mathrm{F}_{2}$ & $17.64+0.26$ & $13.49+0.11$ & $50.14+0.14$ & $52.11+0.17$ \\
\hline $\mathrm{F}_{3}$ & $26.00 \pm 0.19$ & $23.42+0.72$ & $42.31+0.21$ & $44.23+0.25$ \\
\hline $\mathrm{F}_{4}$ & $40.66+0.27$ & $40.71+0.12$ & $40.71+0.12$ & $23.42+0.72$ \\
\hline $\mathrm{F}_{5}$ & $53.81+0.24$ & $24.29+0.21$ & $57.43+0.12$ & $55.71+0.10$ \\
\hline $\mathrm{F}_{6}$ & $27.74+0.25$ & $39.41+0.34$ & $36.47+0.49$ & $42.35+0.59$ \\
\hline $\mathrm{F}_{7}$ & $47.61+0.14$ & $43.71+0.20$ & $23.00+0.09$ & $27.74+0.25$ \\
\hline $\mathrm{F}_{8}$ & $60.00+0.10$ & $61.42+0.04$ & $64.21+0.11$ & $54.75+0.14$ \\
\hline $\mathrm{F}_{9}$ & $29.25+0.21$ & $40.39+0.05$ & $40.31+0.09$ & $45.19+0.08$ \\
\hline $\mathrm{F}_{10}$ & $30.00+0.14$ & $23.00+0.09$ & $52.00+0.04$ & $33.00+0.08$ \\
\hline $\mathrm{F}_{11}$ & $42.95+0.07$ & $12.79+0.30$ & $41.80+0.26$ & $41.85+0.21$ \\
\hline $\mathrm{F}_{12}$ & $39.41+0.11$ & $57.06+0.03$ & $44.12+0.01$ & $50.00+0.09$ \\
\hline
\end{tabular}

\subsection{Surface $p H$}

Surface $\mathrm{pH}$ of the prepared tablets was maintained near to neutral $\mathrm{pH}$, the reason behind is to prevent it from any damage to buccal mucosa lining as shown.

Table 4. pH data of buccal tablets 


\begin{tabular}{|c|c|}
\hline Formulation No & $\overline{\mathrm{pH}}$ \\
\hline$F_{1}$ & $7.0 \pm 0.19$ \\
\hline $\mathrm{F}_{2}$ & $7.2 \pm 0.10$ \\
\hline $\mathrm{F}_{3}$ & $6.5 \pm 0.14$ \\
\hline $\mathrm{F}_{4}$ & $6.6 \pm 0.46$ \\
\hline $\mathrm{F}_{5}$ & $6.5 \pm 0.10$ \\
\hline $\mathrm{F}_{6}$ & $6.8 \pm 0.12$ \\
\hline $\mathrm{F}_{7}$ & $6.5 \pm 0.12$ \\
\hline $\mathrm{F}_{8}$ & $7.0 \pm 0.32$ \\
\hline $\mathrm{F}_{9}$ & $6.9 \pm 0.42$ \\
\hline $\mathrm{F}_{10}$ & $6.3 \pm 0.12$ \\
\hline $\mathrm{F}_{11}$ & $7.1 \pm 0.24$ \\
\hline $\mathrm{F}_{12}$ & $7.2 \pm 0.19$ \\
\hline
\end{tabular}

\subsection{In vitro mucoadhesive force}

Mucoadhesive force depicts the binding of the polymer and the mucin layer of the buccal mucosa when they come in contact with each other. When polymer absorbs more water and more swelling will result in more binding at buccal layer. Carbopol 971 shows greater mucoadhesive properties.

Table 5. Mucoadhesive date of tablets

\begin{tabular}{cc}
\hline Formulation No. & Mucoadhesive force \\
& \\
\hline$F_{1}$ & $22.28 \pm 0.86$ \\
$F_{2}$ & $22.97 \pm 1.48$ \\
$F_{3}$ & $20.54 \pm 0.98$ \\
$F_{4}$ & $23.25 \pm 1.16$ \\
$F_{5}$ & $38.81 \pm 0.28$ \\
\hline
\end{tabular}




\begin{tabular}{ll}
\hline $\mathrm{F}_{7}$ & $32.64 \pm 1.50$ \\
$\mathrm{~F}_{8}$ & $53.10 \pm 0.21$ \\
$\mathrm{~F}_{9}$ & $55.53 \pm 1.63$ \\
$\mathrm{~F}_{10}$ & $32.06 \pm 2.07$ \\
$\mathrm{~F}_{11}$ & $22.98 \pm 2.18$ \\
$\mathrm{~F}_{12}$ & $35.75 \pm 0.39$ \\
\hline
\end{tabular}

\subsection{In-vitro drug release study}

In-vitro drug release of all the prepared tablets was shown. Formulations prepared by using carbopolshow a retarding effect more than other prepared tablets.

Table 6. In-vitro release profile for formulation F1 to F6

\begin{tabular}{|c|c|c|c|c|c|c|c|}
\hline \multirow[t]{2}{*}{ Sr.no } & \multirow{2}{*}{ Time (hr) } & \multicolumn{6}{|c|}{$\%$ Cumulative Drug Released (Mean \pm S.D.) } \\
\hline & & F1 & $\mathrm{F} 2$ & F3 & F4 & F5 & F6 \\
\hline 1 & 0 & $0.00 \pm 00$ & $0.00 \pm 00$ & $0.00 \pm 00$ & $0.00 \pm 00$ & $0.00 \pm 00$ & $0.00 \pm 00$ \\
\hline 2 & 1 & $12.87 \pm 0.45$ & $12.70 \pm 1.08$ & $4.57 \pm 0.37$ & $1.58 \pm 0.50$ & $7.89 \pm 0.12$ & $6.39 \pm 0.43$ \\
\hline 3 & 2 & $28.88 \pm 0.25$ & $19.41 \pm 0.29$ & $14.06 \pm 0.41$ & $10.72 \pm 0.56$ & $11.59 \pm 0.13$ & $14.23 \pm 0.54$ \\
\hline 4 & 3 & $41.66 \pm 0.58$ & $31.14 \pm 0.59$ & $27.92 \pm 0.23$ & $14.10 \pm 0.49$ & $20.78 \pm 0.17$ & $20.29 \pm 0.87$ \\
\hline 5 & 4 & $54.01 \pm 0.76$ & $43.43 \pm 0.54$ & $36.37 \pm 0.45$ & $26.80 \pm 0.43$ & $30.53 \pm 0.18$ & $24.39 \pm 0.67$ \\
\hline 6 & 5 & $63.94 \pm 0.32$ & $54.95 \pm 0.35$ & $46.70 \pm 0.53$ & $35.91 \pm 0.51$ & $44.31 \pm 0.21$ & $44.11 \pm 0.57$ \\
\hline 7 & 6 & $73.75 \pm 0.82$ & $66.37 \pm 0.27$ & $63.40 \pm 0.60$ & $49.06 \pm 0.56$ & $56.01 \pm 0.15$ & $56.64 \pm 0.90$ \\
\hline 8 & 7 & $79.97 \pm 0.94$ & $72.38 \pm 0.43$ & $77.03 \pm 0.45$ & $63.44 \pm 0.34$ & $63.62 \pm 0.18$ & $75.88 \pm 0.34$ \\
\hline 9 & 8 & $88.37 \pm 0.55$ & $86.39 \pm 0.56$ & $80.10 \pm 0.29$ & $95.50 \pm 0.39$ & $69.28 \pm 0.23$ & $98.05 \pm 0.51$ \\
\hline
\end{tabular}

Table 7. In-vitro release profile for formulation F7 to F12

$\%$ Cumulative Drug Released (Mean \pm S.D.)

Sr. no. Time (hr)

\begin{tabular}{llllllll}
\hline & & F7 & F8 & F9 & F10 & F11 & F12 \\
1 & 0 & $0.00 \pm 00$ & $0.00 \pm 00$ & $0.00 \pm 00$ & $0.00 \pm 00$ & $0.00 \pm 00$ & $0.00 \pm 00$ \\
2 & 1 & $8.22 \pm 0.44$ & $4.07 \pm 0.08$ & $0.75 \pm 0.12$ & $11.38 \pm 0.32$ & $1.91 \pm 0.54$ & $2.74 \pm 0.56$ \\
3 & 2 & $16.40 \pm 0.38$ & $9.57 \pm 1.18$ & $3.08 \pm 0.78$ & $15.76 \pm 0.45$ & $9.39 \pm 0.35$ & $5.41 \pm 0.98$ \\
4 & 3 & $27.45 \pm 0.24$ & $16.60 \pm 1.13$ & $10.73 \pm 1.01$ & $25.80 \pm 0.79$ & $12.77 \pm 0.47$ & $13.58 \pm 0.49$ \\
5 & 4 & $35.74 \pm 1.00$ & $25.99 \pm 1.10$ & $15.61 \pm 1.23$ & $36.41 \pm 0.97$ & $27.12 \pm 0.95$ & $28.10 \pm 0.50$ \\
\hline
\end{tabular}




\begin{tabular}{llllllll}
\hline 6 & 5 & $47.72 \pm 0.55$ & $35.43 \pm 0.21$ & $21.34 \pm 1.42$ & $49.72 \pm 0.99$ & $31.58 \pm 0.27$ & $35.89 \pm 0.59$ \\
7 & 6 & $61.77 \pm 0.48$ & $44.42 \pm 0.47$ & $33.24 \pm 1.03$ & $62.95 \pm 0.91$ & $46.04 \pm 0.81$ & $45.89 \pm 0.73$ \\
8 & 7 & $68.75 \pm 0.82$ & $54.13 \pm 1.62$ & $40.57 \pm 0.99$ & $78.24 \pm 0.89$ & $56.75 \pm 0.34$ & $52.95 \pm 0.84$ \\
9 & 8 & $76.10 \pm 0.75$ & $59.91 \pm 1.09$ & $44.94 \pm 0.94$ & $91.95 \pm 0.95$ & $63.04 \pm 0.46$ & $60.38 \pm 0.22$ \\
\hline
\end{tabular}

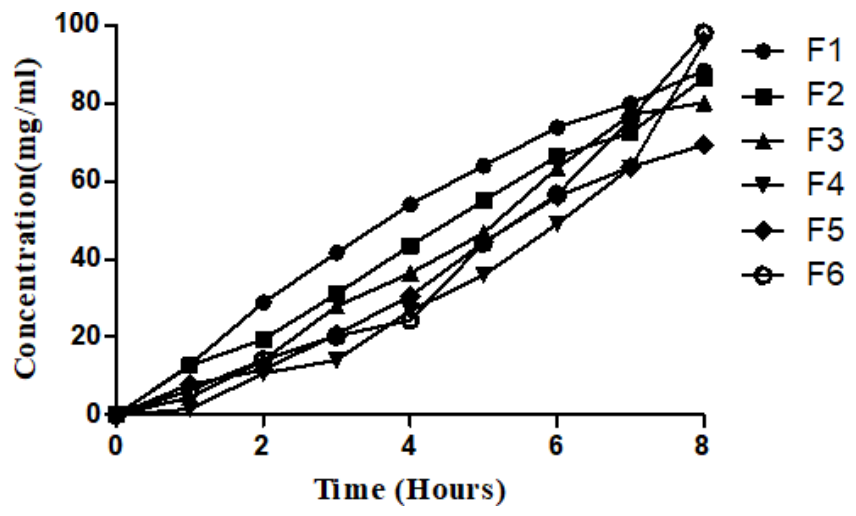

Figure 2. Dissolution data for formulations F1 to F6

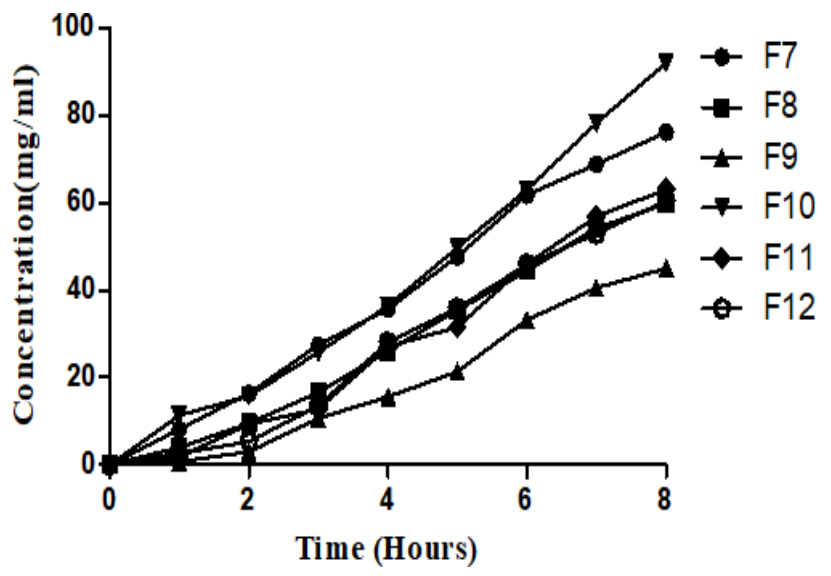

Figure 3. Dissolution dat a for formulations F7 toF12

\section{Conclusion}

Bioadhesive buccal tablets of Flurbiprofen could be prepared by direct compression method using bioadhesive polymers like HPMC K4M, HPMC K15M, Sodiu m carboxy methylcellulose, and carbopol. It is being evident from the prepared formulations that formulation no F8, F9 and F12 which were prepared by using Carbopol 971 shows better $\mathrm{pH}$, mucoadhesive and release retarding effect. So, it is concluded that carbopol have excellent water retaining properties and it also retards the drug that is why further can be used in buccal controlled drug delivery system.

\section{Conflict of Interest}

All the authors declare no conflict of interest. 


\section{Acknowledgment}

This work has been supported, by Johar Institute of Profes sional Studies (JIPS), Lahore, Pakistan.

\section{References}

Darwish, M. K. and A. N. Elmeshad (2009). "Buccal mucoadhesive tablets of flurbiprofen: Characterization and optimization." Drug discoveries \& therapeutics 3(4).

Gupta, S., I. Singhvi, M. Shirsat, G. Karwani and A. Agarwal (2011). " Buccal adhesive drug delivery system: a review." Asian J. Biochemical and pharmaceutical research2011 2(1): 105-114.

Kadam, S., D. Yeole, H. Unjavani, A. Ganure and R. Kabra (2014). "Formulation and Evaluation of Mucoadhesive Buccal Tablets Containing Carvedilol." Int J Curr Pharm Res 1: 67-80.

Manogna, K., P. Nagaveni and K. Thyagaraju "A Review On Mucoadhesive Bilayer Buccal Tablets."

Patel, D. M., P. M. Shah and C. N. Patel (2014). "Formulation and evaluation of bioadhesive buccal drug delivery of repaglinide tablets." Asian Journal of Pharmaceutics (AJP): Free full text articles from Asian J Pharm 6(3).

Reddy, R. J., M. Anjum and M. A. Hussain (2013). "A comprehensive review on buccal drug delivery system." Am J Advan Drug Deliv 1: 300-312.

Singh, J. and P. Deep (2013). "A review article on mucoadhesive buccal drug delivery system." International journal of pharmaceutical sciences and research 4(3): 916. 